\title{
Effect of Particle Size Distribution on Laser Powder Bed Fusion Manufacturability of Copper
}

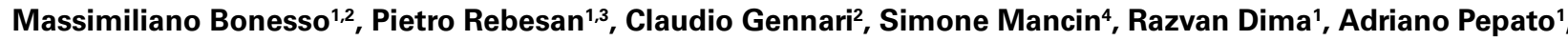 \\ and Irene Calliari²
}

\begin{abstract}
${ }^{1}$ National Institute for Nuclear Physics (INFN) - Padova Division, Padova, Italy ${ }^{2}$ Department of Industrial Engineering (DII), University of Padua, Padova, Italy ${ }^{3}$ Department of Mechanical Engineering, Politecnico di Milano, Milan, Italy ${ }^{4}$ Department of Management and Engineering (DTG), University of Padua, Vicenza, Italy
\end{abstract}

Received March 5, 2021; accepted March 29, 2021; published online April 21, 2021

\begin{abstract}
One of the major benefits of the Laser Powder Bed Fusion (LPBF) technology is the possibility of fabrication of complex geometries and features in only one-step of production. In the case of heat exchangers in particular, this is very convenient for the fabrication of conformal cooling channels which can improve the performance of the heat transfer capability. Yet, obtaining dense copper parts printed via LPBF presents two major problems: the high reflectivity of $1 \mu \mathrm{m}$ (the wavelength of commonly used laser sources) and the high thermal conductivity of copper that limits the maximum local temperature that can be attained. This leads to the formation of porous parts.

In this contribution, the influence of the particle size distribution of the powder on the physical and mechanical properties of parts produced via LPBF is studied. Three copper powders lots with different particle size distributions are used in this study. The effect on densification from two laser scan parameters (scan speed and hatching distance) and the influence of contours scans on the lateral surface roughness is reported. Subsequently, samples manufactured with the optimal process parameters are tested for thermal and mechanical properties evaluation.
\end{abstract}

Keywords: Copper, Additive Manufacturing, Laser Powder Bed Fusion, Particle Size Distribution, Porosity

Wirkung der Verteilung der Partikelgrösse auf die Herstellbarkeit von Kupfer im Laserpulverbett

Zusammenfassung: Einer der Hauptvorteile der LPBF-Technologie (Laser Powder Bed Fusion) ist die Möglichkeit, kom-

Eng. M. Bonesso ( $₫)$

National Institute for Nuclear Physics (INFN)-Padova Division, Via Francesco Marzolo, 8,

35131 Padova, Italy

massimiliano.bonesso@pd.infn.it plexe Geometrien und Merkmale in nur einem Produktionsschritt herzustellen. Insbesondere im Fall von Wärmetauschern ist dies sehr praktisch für die Herstellung von konformen Kühlkanälen, die die Leistung der Wärmeübertragungsfähigkeit verbessern können. Das Erhalten von dichten Kupferteilen, die über LPBF gedruckt werden, stellt jedoch zwei Hauptprobleme dar: das hohe Reflexionsvermögen von $1 \mu \mathrm{m}$ (die Wellenlänge üblicherweise verwendeter Laserquellen) und die hohe Wärmeleitfähigkeit von Kupfer, die die maximal erreichbare lokale Temperatur begrenzt. Dies führt zur Bildung poröser Teile.

In diesem Beitrag wird der Einfluss der Partikelgrößenverteilung des Pulvers auf die physikalischen und mechanischen Eigenschaften von über LPBF hergestellten Teilen untersucht. In dieser Studie werden drei Kupferpulverchargen mit unterschiedlichen Partikelgrößenverteilungen verwendet. Der Einfluss von zwei Laser-Scan-Parametern (Scan-Geschwindigkeit und Schraffurabstand) auf die Verdichtung und der Einfluss von Kontur-Scans auf die Rauheit der Seitenoberfläche wird angegeben. Anschließend werden mit den optimalen Prozessparametern hergestellte Proben zur Bewertung der thermischen und mechanischen Eigenschaften getestet.

Schlüsselwörter: Kupfer, Additive Fertigung, Laser Pulverbettfusion, Partikelgrößenverteilung, Porosität

\section{Introduction}

ISO/ASTM 52900 defines the Powder Bed Fusion (PBF) as the additive manufacturing process in which thermal energy selectively fuses regions of a powder bed [1]. For metallic materials, if the power source is a high intensity laser, the technique is called Laser Powder Bed Fusion (LPBF) or Selective Laser Melting (SLM). 
Like all the additive manufacturing processes, which fabricate parts in a layer-by-layer manner, the geometric freedom offered by the LPBF process allows the realization of metal components with optimized performance [2]. Thermal management is one of the applications that has attracted more interest, since the possibility of manufacturing conformal cooling channels and mesh structures, to increase the surface to volume ratio, could enhance the efficiency of heat exchangers [3]. NASA has already produced demonstration combustion chambers with an internal cooling channel [4], and also in the field of high energy physics, there is a high interest in improving the efficiency of heat flux components [5].

The high thermal conductivity $\left(401 \mathrm{~W} /(\mathrm{m} \cdot \mathrm{K})\right.$ at $\left.27^{\circ} \mathrm{C}\right)$ of pure copper makes it the ideal material for thermal application, but it is also one of the reasons why it is difficult to process by LPBF. The fast heat dissipation from the melt pool leads to the balling effect [6], and the high reflectivity at near infra-red drastically reduces the incoming thermal energy needed to melt the material, resulting in porous part with un-melted particles [7]. In order to overcome this issue, different approaches have been studied: high density parts (>98\%) were manufactured using higher laser power (up to $1000 \mathrm{~W}$ ) [6,8] and the use of a green laser $(515 \mathrm{~nm})$ for which copper has lower reflectivity is investigated by Fraunhofer for Laser Technology ILT [9]. These approaches for printing pure copper, however, are not suitable for commercially available LPBF machines, which have a low laser power (400W Max) and laser wavelength of around $1080 \mathrm{~nm}$. Therefore, an alternative solution is to modify the starting powder instead of the laser. Jadhav obtained dense copper part with high electrical and mechanical properties using oxidized copper powder and $500 \mathrm{~W}$ of laser power [10]. The effect of the particle size distribution (PSD) is also an important process parameter that influences the quality of the final part, powders with finer particles are easier to melt and also have lower optical reflectivity [11]. The feasibility of the SLM production of dense pure copper parts at low laser power (max 200W) was demonstrated utilizing a finer distribution of powders [12].

This contribution analyses the processability by means of an LPBF machine with a low laser output (370W) of pure copper powders with a different granulometry. The effect of hatching distance and laser scan speed on the relative density has been analysed. A contour scan strategy has been tested for the improvement of the lateral surface finishing. Finally, the optimal process parameters has been used to manufacture samples for the characterization of mechanical and thermal properties.

\section{Materials and Methods}

\subsection{Powder Characterization}

In the present research, gas atomized copper powders with three different particle size distribution were tested. The powders were supplied from different producers, labelled $A, B$, and $C$. The chemical composition and laser diffraction data of the powders have been provided by the manufacturers and are listed in Table 1. The chemical composition of Powder $\mathrm{C}$ presented higher concentration of impurities: O $0.25 \%$, Zn $0.07 \%, \mathrm{P} 0.06 \%$, and Sn $0.05 \%$. Powder A corresponds to a standard $15-45 \mu \mathrm{m}$ product, while Powder $\mathrm{C}$ presents a similar distribution (same SPAN index) but with finer particles. The reduction of particle size increases the surface area to absorb more laser energy [13], moreover a larger ratio between beam size and the irradiated sphere increases the opportunity for multiple reflections, which increases the absorptivity, especially for high conductive materials [14]. Powder B has a broader particle size distribution (higher SPAN index) towards fine particles. Broad PSD leads to a higher powder bed density that favours the densification process [15], but also enhances the thermal conductivity of the powder [16], which is a drawback in the case of pure copper. Also, the presence of smaller particles favours the agglomeration and reduces the powder flowability, which hinders the realization of a homogenous powder bed. The powder flowability was tested with the Hall flowmeter funnel, and only the powder with standard PSD presented a flow rate of $19.1 \pm 1.2 \mathrm{~s} / 50 \mathrm{~g}$, while the powders with finer particles did not flow.

Fig. 1 shows the morphology of the powders observed by SEM, which was mainly spherical. Overall, Powder A presented fewer particles with an irregular shape and a higher concentration of satellite particles attached to larger copper powder particles. Powders with lower SPAN index (Powders $A$ and $C$ ) had a more uniform distribution of particle size, and it was also observed that the finer particles in Powder B had a higher tendency to agglomerate, as reported in Fig. 1b. EDS analyses have been performed to check the chemical composition of the powders (Fig. 2). It was found that particles with irregular shapes presented superficial oxidation.

\subsection{LPBF Setup and Experimental Plan}

All the specimens were manufactured by EOSINT M280 powder bed machine, equipped with a $400 \mathrm{~W}$ ytterbium fibre laser. The laser beam focus was $82 \mu \mathrm{m}$ in diameter with Gaussian profile and a wavelength of $1064 \mathrm{~nm}$. Stainless steel (AISI 304L) platforms were used as a substrate and

\begin{tabular}{|llllll}
\hline \multicolumn{7}{|l}{$\begin{array}{l}\text { TABLE } 1 \\
\text { Chemical composition and particle size distribution of the copper powders }\end{array}$} \\
\hline \multicolumn{7}{|l}{$\mathrm{Cu} \%$} & $\mathrm{D} 10[\mu \mathrm{m}]$ & $\mathrm{D} 50[\mu \mathrm{m}]$ & $\mathrm{D} 90[\mu \mathrm{m}]$ & SPAN (D90-D10)/D50 \\
\hline Powder A & 99.96 & 18.5 & 27.4 & 40.6 & 0.81 \\
\hline Powder B & 99.95 & 8.1 & 18.7 & 36.4 & 1.51 \\
\hline Powder C & 99.57 & 12.5 & 19.5 & 28.2 & 0.81 \\
\hline
\end{tabular}



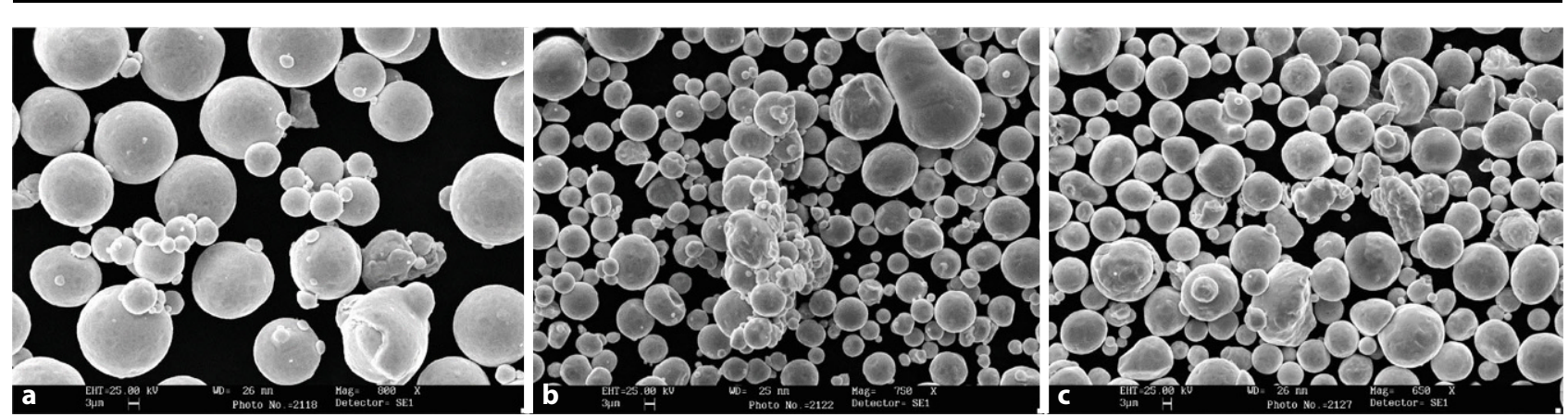

Fig. 1: Secondary electron image of copper powder with PSD: a Powder A 19-41 $\mu \mathrm{m}$; b Powder B 8-36 $\mu$; c Powder C 13-28 $\mu \mathrm{m}$

Fig. 2: EDS analysis of PowderC: a spherical particle; b particle with irregular shape

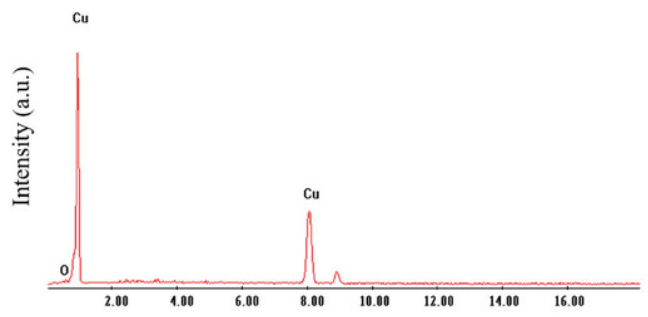

a

Energy $(\mathrm{eV})$

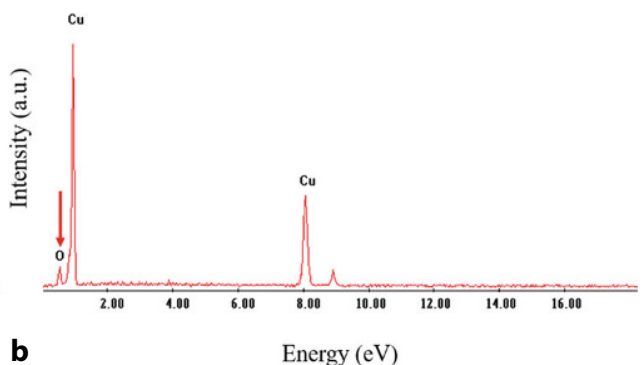

were heated to $40^{\circ} \mathrm{C}$. Compared to copper platforms, steel guarantees a higher thermal stability due to the lower thermal conductivity, and higher relative densities are obtained for the same energy input [6]. Argon was used as protective gas and the oxygen content was kept below $0.2 \%$ during the manufacturing process. The recoater blade used is made of a high speed steel and no powder flowability issues have been observed during the recoating.

Since one of the main problems of LPBF of pure copper is the lack of fusion, it was decided for the production of the density specimens $\left(10 \times 10 \times 10 \mathrm{~mm}^{3}\right)$ to change only the scan speed $(\mathrm{v})$ between 200 and $500 \mathrm{~mm} / \mathrm{s}$ and hatching distance $(\mathrm{h})$ between 80 and $110 \mu \mathrm{m}$, while the laser power $(\mathrm{P})$ and the layer thickness $(\mathrm{t})$ were kept at $370 \mathrm{~W}$ and $20 \mu \mathrm{m}$ to maximize the volumetric energy density input $(E)$ :

$$
E=\frac{P}{\text { hůvůt }}
$$

A bidirectional $5 \mathrm{~mm}$ stripe pattern with a rotation angle of $67^{\circ}$ were selected as the scan strategy for all the specimens and the effect of the contour scan strategy on the lateral surface roughness was observed with a portable roughness gauge RUGOSURF 10G, following the ISO 4288:2000 standard. The measurements were performed on the lateral surface of samples with the dimensions of $20 \times 2 \times 10 \mathrm{~mm}$. Two contours scan were traced by the laser, one on the original CAD geometry contour and one with a hatch distance of $0.08 \mathrm{~mm}$ towards the inside. The measurements were repeated eight times through the build direction and the average values were reported.

To measure the densities of all samples, the Archimedes method was used and relative densities were calculated by dividing the measured densities with the theoretical density of copper $\left(8.96 \mathrm{~g} / \mathrm{cm}^{3}\right)$ [17]. Selected specimens were polished and chemical etched with a solution of $1 \mathrm{ml} \mathrm{HCl}$,
$2.5 \mathrm{~g} \mathrm{FeCl}_{3}$, and $100 \mathrm{ml} \mathrm{EtOH}$ and observed at the optical microscope. Micro-hardness measurements were performed on the samples on a Leitz Miniload 2 (Leica Microsystem S.r.I., Milan, Italy) micro-hardness tester with $300 \mathrm{~g}$ load.

Finally, specimens for thermal conductivity measurements and tensile tests were manufactured using the optimized parameters. The thermal diffusivity was measured by means of a Transient Hot Disk TPS 2500 S, the measure was repeated 10 times and the average value was considered. The thermal conductivity was calculated as follows:

$$
\lambda=\operatorname{aů} c_{p} \stackrel{\circ}{\rho} \rho
$$

Where $\lambda$ is thermal conductivity $(\mathrm{W} / \mathrm{m} / \mathrm{K}), a$ is thermal diffusivity $\left(\mathrm{mm}^{2} / \mathrm{s}\right), \mathrm{c}_{\mathrm{p}}$ is the heat capacity of pure copper $(0.385 \mathrm{~J} / \mathrm{g} / \mathrm{K})[17]$, and $\rho$ is the density of the specimen $\left(\mathrm{g} / \mathrm{cm}^{3}\right)$.

Cylindrical dog bone tensile specimens with a geometry in accordance with ASTM E8/E8M-16a standard were produced in both horizontal ( $X Y$ plane) and vertical ( $X Z$ plane) directions. The specimens were machined to a gauge length of $24 \mathrm{~mm}$ and a diameter of $6 \mathrm{~mm}$. Four specimens for each condition were tested on an MTS 858 Mini Bionix II with a displacement rate of $0.45 \mathrm{~mm} / \mathrm{min}$. The strain was measured with an MTS extensometer 632.29F-30 with a gauge length of $5 \mathrm{~mm}$.

\section{Results and Discussion}

\subsection{Relative Density and Optical Inspection}

The results of the parameters' optimisation for the realization of dense copper parts are reported in Fig. 3. All the density specimens were manufactured in an acceptable condi- 
Fig. 3: Relative density of the samples manufactured with different scan speed and three different powder suppliers. a $19-41 \mu \mathrm{m} ; \mathbf{b} 8-36 \mu \mathrm{m}$; c $13-28 \mu \mathrm{m}$ hatching distance, for the
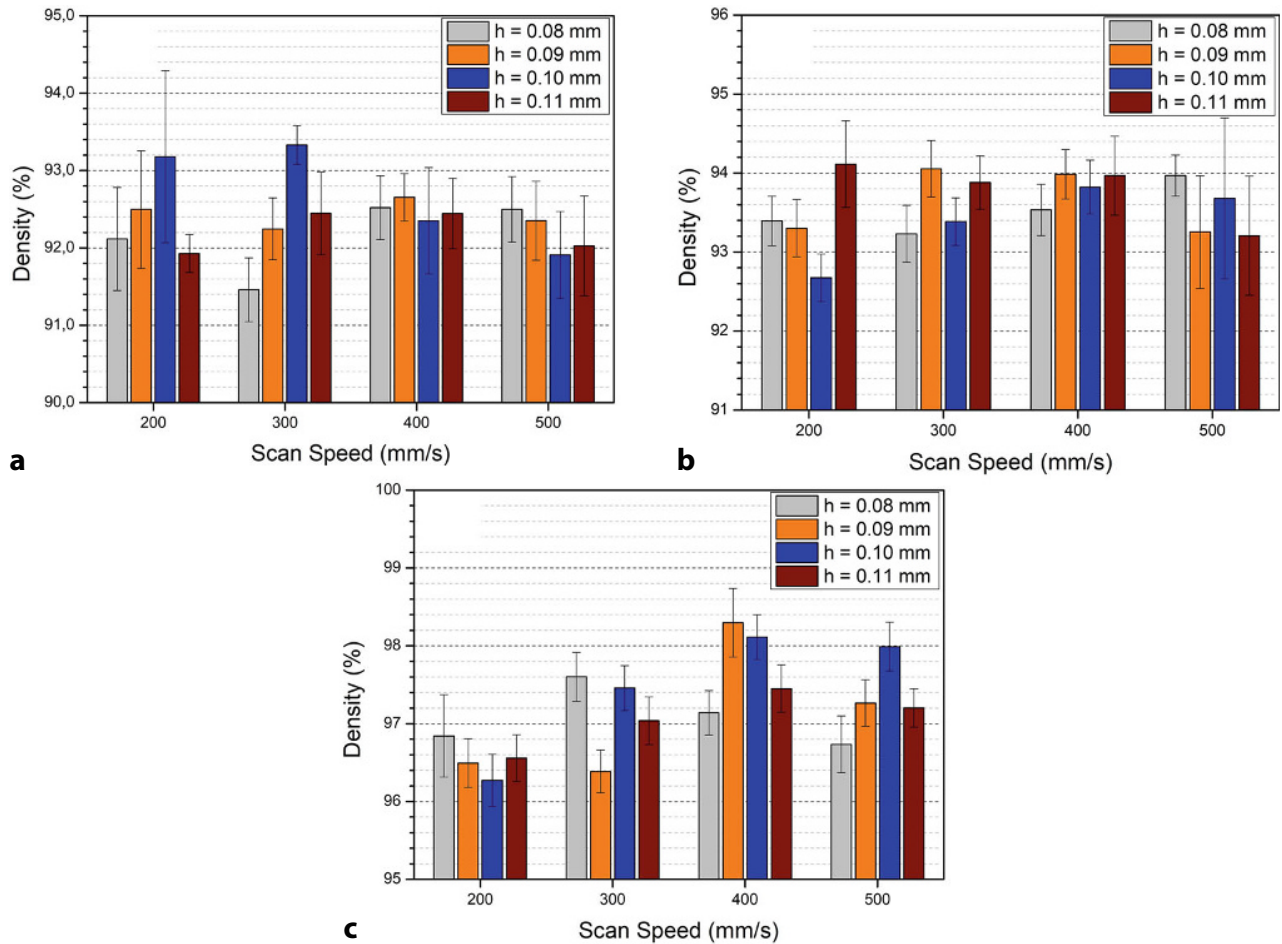

Fig. 4: Optical microscope analysis of the density specimens $(400 \mathrm{~mm} / \mathrm{s}$ scan speed and $0.09 \mathrm{~mm}$ hatching distance) after etching in horizontal xy plane: a $19-41 \mu \mathrm{m}$; b $8-36 \mu \mathrm{m}$; c 13-28 $\mu \mathrm{m}$. d Micro-hardness values of the observed surfaces
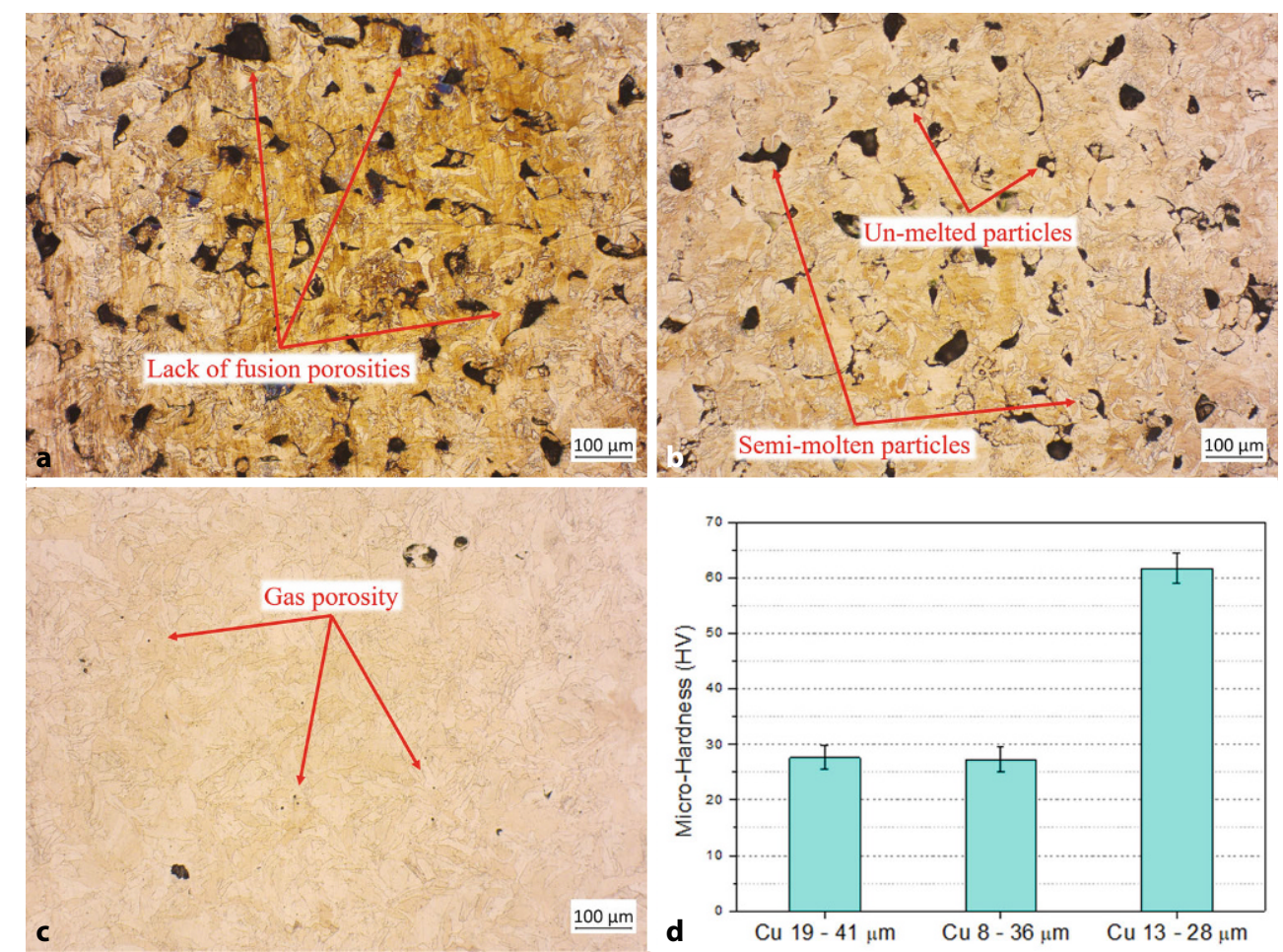

tion, without evident defects. For each powder, the modification of the parameters did not involve high variation of the measured relative densities ( $2 \%$ maximum), while higher differences have been observed between powders. With a standard size distribution, it was possible to obtain relative densities of around $92 \%$, with a maximum of $93.3 \%$ with $300 \mathrm{~mm} / \mathrm{s}$ scan speed and 0.1 hatching distance. An improvement of about $1 \%$ has been achieved using Powder B. The best results were obtained with Powder C, the maximum relative density obtained with this powder was $98.3 \%$ with $400 \mathrm{~mm} / \mathrm{s}$ scan speed and $0.09 \mathrm{~mm}$ hatching distance. This improvement, however, could be attributed not only to the finer PSD but also to the chemical composition of the powder. The high concentration of impurities, es- 


\begin{tabular}{|lll|}
\hline $\begin{array}{l}\text { TABLE } 2 \\
\text { Effect of the contour scan strategy on the lateral surface roughness of samples produced with copper powders } \\
\text { with different PSD }\end{array}$ \\
\hline & $\begin{array}{l}\text { No contour } \\
\mathrm{R}_{\mathrm{a}}[\mu \mathrm{m}]\end{array}$ & $\begin{array}{l}\text { Contour } \\
\mathrm{R}_{\mathrm{a}}[\mu \mathrm{m}]\end{array}$ \\
\hline Powder A $(19-41 \mu \mathrm{m})$ & $11.5 \pm 0.7$ & $11.7 \pm 0.9$ \\
\hline Powder B $(8-36 \mu \mathrm{m})$ & $11.1 \pm 0.8$ & $10.9 \pm 0.7$ \\
\hline Powder C $(13-28 \mu \mathrm{m})$ & $12.0 \pm 0.7$ & $2.9 \pm 0.7$ \\
\hline
\end{tabular}

\begin{tabular}{|c|c|c|c|}
\hline & $\begin{array}{l}\mathrm{E} \\
{[\mathrm{GPa}]}\end{array}$ & $\begin{array}{l}\sigma(0.2 \%) \\
{[\mathrm{MPa}]}\end{array}$ & $\begin{array}{l}\text { UTS } \\
\text { [MPa] }\end{array}$ \\
\hline $\mathrm{Cu} 19-41 \mu \mathrm{m} \mathrm{H}$ & $109.2 \pm 1.9$ & $113.3 \pm 0.5$ & $160.2 \pm 1.7$ \\
\hline $\mathrm{Cu} 19-41 \mu \mathrm{m} \mathrm{V}$ & $85.2 \pm 1.5$ & $89.0 \pm 1.2$ & $102.8 \pm 1.8$ \\
\hline $\mathrm{Cu} 8-36 \mu \mathrm{m} \mathrm{H}$ & $101.8 \pm 3.1$ & $97.5 \pm 2.4$ & $138.8 \pm 2.5$ \\
\hline $\mathrm{Cu} 8-36 \mu \mathrm{m} \mathrm{V}$ & $77.2 \pm 2.2$ & $74.3 \pm 0.5$ & $83.9 \pm 1.9$ \\
\hline $\mathrm{Cu} 13-28 \mu \mathrm{m} \mathrm{H}$ & $155.4 \pm 1.5$ & $254.8 \pm 3.0$ & $312.7 \pm 2.7$ \\
\hline $\mathrm{Cu} 13-28 \mu \mathrm{m} \mathrm{V}$ & $149.8 \pm 0.7$ & $237.8 \pm 4.3$ & $259.3 \pm 13.3$ \\
\hline
\end{tabular}

\begin{tabular}{|c|c|}
\hline & $\begin{array}{l}\text { Thermal conductivities } \\
{[\mathrm{W} / \mathrm{mK}]}\end{array}$ \\
\hline Powder A & $136.9 \pm 0.4$ \\
\hline Powder B & $139.1 \pm 0.4$ \\
\hline Powder C & $227.8 \pm 2.5$ \\
\hline
\end{tabular}

pecially phosphorous $[18,19]$, reduces the electrical and thermal conductivity of copper which decreases heat dissipation and improves the densification.

Overall, for all three kinds of powders, high densities were obtained with $400 \mathrm{~mm} / \mathrm{s}$ scan speed and $0.09 \mathrm{~mm}$ hatching distance and a corresponding energy density of $514 \mathrm{~J} / \mathrm{mm}^{3}$. These parameters have been chosen to produce specimens for testing the surface roughness, tensile properties, and thermal conductivity.

Optical images of these samples are reported in Fig. 4. Samples produced with Powders A and B presented several fragmented pores due to the lack of fusion of adjacent scan tracks. Semi-molten particles inside the pores were also observed, along with un-melted particles englobed in the copper matrix. These particles improve the density of the sample but do not contribute to the mechanical properties of the material. These defects have been also observed in the sample produced with Powder $C$ but with a lower concentration. Fig. $4 \mathrm{c}$ also illustrates the presence of small circular pores associated with gas entrapment. The microstructure of the samples was equiassic with fine grain.

The average values of five measurements of the micro-hardness are reported in Fig. 4d. As expected, the densest sample showed the highest value of $61.7 \mathrm{HV}$, more than double of the others, respectively $27.6 \mathrm{HV}$ with PSD 19-41 $\mu \mathrm{m}$ and $27.3 \mathrm{HV}$ with PSD 8-36 $\mu \mathrm{m}$. Annealed unalloyed copper has a hardness in the range between 40 and $120 \mathrm{HV}$, depending on the level of cold working [18]. The value obtained with Powder $C$ is in the range of annealed pure copper (between 40 and $65 \mathrm{HV}$ ), while the low values observed with Powders $A$ and $B$ are due to the high concentration of lack of fusion porosities.

\subsection{Lateral Surface Roughness}

Table 2 reports the lateral surface roughness measurements. The effect of the contour scan strategy strictly depends on the PSD of the powders. Powders with larger particles did not show any improvement in the reduction of surface roughness, the average surface roughness measured was $\sim 11 \mu \mathrm{m}$, regardless of the scan strategy performed. A significant improvement was found with the PSD $13-28 \mu \mathrm{m}$, from 12 to $2.9 \mu \mathrm{m}$ with the contour scan strategy. This improvement could be attributed to the fact that Powder $\mathrm{C}$ forms a stable melt pool, and the fine particles attached to it do not influence the roughness as the larger particles present in the other powders.

\subsection{Mechanical and Thermal Properties}

The average results of tensile tests are reported in Table 3 and stress-strain curves of representative samples are shown in Fig. 5. The mechanical properties of all the specimens built in the horizontal direction were higher compared to the ones manufactured in the vertical direction. The anisotropy is caused by the presence of lack of 


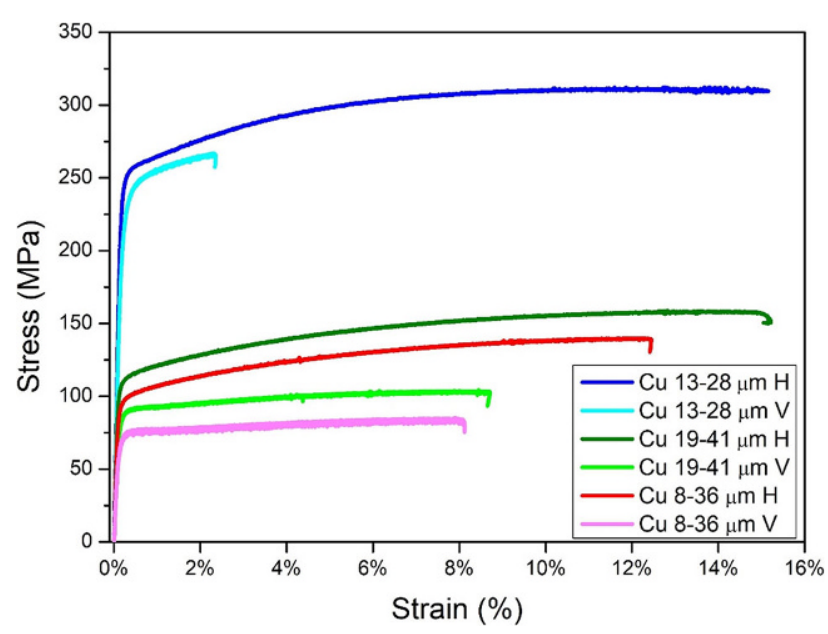

Fig. 5: Stress-strain curves of onecopper tensile specimensfor each powderlot

fusion porosities, which severely diminishes the interlayer bonding. Of course, parts built vertically are manufactured with more layers, so their mechanical properties are severely affected. As a matter of fact, the samples with higher porosities exhibited higher reductions of mechanical properties: the reduction of the yield strength was $21 \%$ with Powder A, 24\% with Powder B, and only $7 \%$ with Powder $\mathrm{C}$ (densest sample). Yet, the percentage of elongation of the vertical sample produced with Powder $\mathrm{C}$ was drastically reduced to $\sim 2.36 \%$ (the percentage elongation of the sample manufactured horizontally was higher than the maximum displacement of the extensometer, so the value is not reported). Samples manufactured with Powder B showed the lowest mechanical properties, which demonstrates that the density increase was mainly due to the presence of un-melted particles englobed in the material which do not have a beneficial effect on mechanical properties.

As observed with the micro-hardness measurements, samples produced with Powders A and B showed inferior mechanical properties compared to annealed pure copper, while the values obtained with Powder $\mathrm{C}$ could be compared to pure copper with $\sim 20 \%$ cold working deformation [18].

Finally, Table 4 reports the values of thermal conductivities obtained from the measurements of the thermal diffusivities of the samples.

All the samples exhibited low thermal conductivities compared to pure copper $\left(401 \mathrm{~W} /(\mathrm{m} \cdot \mathrm{K})\right.$ at $\left.27^{\circ} \mathrm{C}\right)$. The reason for the low values measured on the samples obtained with Powders $A$ and $B$ can be attributed to the high concentration of lack of fusion porosities. Porosity reduces the thermal conductivity of copper [20], and furthermore the presence of un-melted particles with oxidized surface can further reduce the thermal conductivity. The sample manufactured using Powder $\mathrm{C}$ showed a thermal conductivity of $227.8 \mathrm{~W} / \mathrm{mK}$, in this case the reduction of the conductivity could be due to the chemical composition of the starting powder and to the presence of porosities and un-melted particles (in less amount).

\section{Conclusions}

This contribution investigates the fabrication by LPBF of copper parts using powders with different particle size distribution. The results show that the PSD impacts the performance of the printed parts in terms of density, surface roughness, and mechanical and thermal properties.

With a standard PSD distribution (Powder A), it was possible to obtain a relative density of $93.3 \%$, tensile strength of $160 \mathrm{MPa}$ (horizontal direction), and thermal conductivity of $\sim 137 \mathrm{~W} /(\mathrm{m} \cdot \mathrm{K})$. Parts fabricated with Powder B showed higher densities and similar thermal conductivity, but lower mechanical properties. This was probably due to the higher concentration of un-melted particles englobed inside the bulk.

Superior performances were observed with Powder C. The powder was characterized by a fine PSD and a higher concentration of impurities, which decreases the thermal conductivity of the powder and improves the densification. A relative density of $98.3 \%$ was obtained by changing scan speed and hatching distance. An improvement of the surface finishing was possible by using a contour scan strategy ( $R_{a}$ from 12 to $2.9 \mu \mathrm{m}$ ). The reduction of lack of fusion porosities granted better thermal and mechanical properties. In fact, despite the lower purity of the starting powder, the measured thermal conductivity of the printed parts was higher $(228 \mathrm{~W} /(\mathrm{m} \cdot \mathrm{K}))$. The mechanical properties of the printed parts can be compared with a $20 \%$ cold worked pure copper.

Finally, samples produced vertically had lower mechanical properties compared to the ones produced horizontally. Samples produced with Powders A and B showed higher reductions in terms of yield strength and tensile strength, while vertical samples produced with Powder $\mathrm{C}$ presented higher reductions of percentage elongation.

Funding. Open access funding provided by Università degli Studi di Padova within the CRUI-CARE Agreement.

Open Access This article is licensed under a Creative Commons Attribu tion 4.0 International License, which permits use, sharing, adaptation, distribution and reproduction in any medium or format, as long as you give appropriate credit to the original author(s) and the source, provide a link to the Creative Commons licence, and indicate if changes were made. The images or other third party material in this article are included in the article's Creative Commons licence, unless indicated otherwise in a credit line to the material. If material is not included in the article's Creative Commons licence and your intended use is not permitted by statutory regulation or exceeds the permitted use, you will need to obtain permission directly from the copyright holder. To view a copy of this licence, visit http://creativecommons.org/licenses/by/4.0/.

\section{References}

1. ISO/ASTM 52900: Standard Terminology for Additive Manufacturing-General Principles-Terminology, ASTM International, 2015

2. Yap, C. Y.; Chua, C. K.; Dong, Z. L.; Liu, Z. H.; Zhang, D. Q.; Loh, L. E.; Sing, S. L.: Review of selective laser melting: Materials and applications, Applied Physics Reviews, 2 (2015), no 041101

3. Tran, T. Q.; Chinnappan, A.; Lee, J. K. Y.; Loc, N. H.; Tran, L. T.; Wang, G.; Kumar, V. V.; Jayathilaka, W. A. D. M.; Ji, D.; Doddamani, M.; Ramakrishna, S.: 3D printing of highly pure copper, Metals, 9 (2019), pp 12-20 
4. Gradl, P. R.; Protz, C. S.; Cooper, K.; Ellis, D.; Evans, L. J.; Garcia, C.: GRCop-42 Development and Hot-fire Testing Using Additive Manufacturing Powder Bed Fusion for Channel-cooled Combustion Chambers, in: AIAA Propulsion and Energy 2019 Forum, Indianapolis, Indiana, USA 2019

5. Zinkle, S. J.: Applicability of copper alloys for DEMO high heat flux components, Physica Scripta, 2016 (2016), no T167

6. Colopi, M.; Demir, A. G.; Caprio, L.; Previtali, B.: Limits and solutions in processing pure $\mathrm{Cu}$ via selective laser melting using a highpower single-mode fiber laser, International Journal of Advanced Manufacturing Technology, 104 (2019), pp 2473-2486

7. Trevisan, F; Calignano, F; Lorusso, M.; Lombardi, M.; Manfredi, D.; Fino, P.: Selective laser melting of chemical pure copper powders, in: Proceedings Euro PM 2017: International Powder Metallurgy Congress and Exhibition, Milan, Italy, 2017

8. Jadhav, S. D.; Dadbakhsh, S.; Goossens, L.; Kruth, J. P.; Van Humbeeck, J.; Vanmeensel, K.: Influence of selective laser melting process parameters on texture evolution in pure copper, Journal of Materials Processing Technology, 270 (2019), pp 47-58

9. Heussen, D.: Meiners, W.: Green Light for New 3D Printing Process, (2017), https://www.ilt.fraunhofer.de/en/press/press-releases/pressrelease-2017/press-release-2017-08-30.html (16.02.2021)

10. Jadhav, S. D.; Vleugels, J.; Kruth, J.; Van Humbeeck, J.; Vanmeensel, K.: Mechanical and electrical properties of selective laser melted parts produced from surface oxidized copper powder, Material Design \& Processing Communications, 2 (2019), no e94

11. Khan, M.; Dickens, P.: Selective laser melting (SLM) of gold (Au), Rapid Prototyping Journal, 18 (2012), pp 81-94

12. Sinico, M.; Cogo, G.; Benettoni, M.; Calliari, I.; Pepato, A.: Influence of powder particle size distribution on the printability of pure copper for selective laser melting, in: 30th Annual International Solid Freeform Fabrication Symposium, Austin, Texas, USA 2019, pp 657-667
13. Simchi, A.: The role of particle size on the laser sintering of iron powder, Metallurgical and Materials Transactions B, 35 (2004), pp 937-948.

14. King, W. E.; Anderson, A. T.; Ferencz, R. M.; Hodge, N. E.; Kamath C.; Khairallah, S. A.; Rubenchik, A. M.: Laser powder-bed fusion additive manufacturing of metals; physics, computational, and materials challenges, Applied Physics Reviews, 2 (2015), no 041304, pp 461-506

15. Vock, S.; Klöden, B.; Kirchner, A.; Weißgärber, T.; Kieback, B.: Powders for powder bed fusion: a review, Progress in Additive Manufacturing, 4 (2019), pp 383-397

16. Sun, S.; Brandt, M.; Easton, M.: Powder bed fusion processes, in Brandt, $M$ (ed.): Laser additive manufacturing: materials, design, technologies, and applications, 1. ed., Woodhead Publishing, 2017, pp 55-77

17. Lide, D. R. (ed.): CRC Handbook of Chemistry and Physics, Internet Version 2005, CRC Press, Boca Raton, Florida, 2005, pp 756-812

18. Chapman, D.: High Conductivity Coppers for Electrical Engineering, Copper Development Association Publication No 122, European Copper Institute Publication No Cu023, 2016, pp 1-30

19. Jadhav, S. D.; Dadbakhsh, S.; Vleugels, J.; Hofkens, J.; Puyvelde, P. Van; Yang, S.; Kruth, J. P.; Van Humbeeck, J.; Vanmeensel, K.: Influence of carbon nanoparticle addition (and impurities) on selective laser melting of pure copper, Materials, 12 (2019), no 15, p 2469

20. Vincent, C.; Silvain, J. F.; Heintz, J. M.; Chandra, N.: Effect of porosity on the thermal conductivity of copper processed by powder metallurgy, Journal of Physics and Chemistry of Solids, 73 (2012), pp 499-504

Publisher's Note. Springer Nature remains neutral with regard to jurisdictional claims in published maps and institutional affiliations. 